Legal Issues in the Digital Age. 2021. Vol. 2, no. 4

Research article

UDC: 342

DOI: $10.17323 / 2713-2749.2021 .4 .34 .69$

\title{
Sharing Radio Spectrum for Research and Innovation
}

\section{目Jos Dumortier',}

目 Irina Yurievna Bogdanovskaya ${ }^{2}$,

目 Niels Vandezande ${ }^{3}$,

\section{股 Mikail Yakushev 4}

${ }^{1}$ Timelex Lawyers, Brussels, Belgium.

2,4 National Research University Higher School of Economics, Moscow, Russia.

${ }^{3}$ Timelex Lawyers, Brussels, Belgium.

1 Jos.dumortier@timelex.eu.

2 ibogdanovskaia@hse.ru, ORCID: 0000-0002-6243-4301

${ }^{3}$ Niels.vandezande@timelex.eu.

${ }^{4}$ myakushev@hse.ru

\section{䟚目 Abstract}

In most countries academic researchers have access to advanced academic telecommunications networks and infrastructures to test and demonstrate the results of their research work. These networks are usually funded by national or regional public authorities. To provide access to the academic networks on a wider scale, European and international collaboration initiatives have been taken. For the fixed network environment this may suffice but the situation is different in the wireless context, partly because here, researchers must, in one way or another, obtain spectrum usage rights. Today spectrum usage rights can be quite easily obtained in the restricted territorial space of a testbed. Yet, small-scale testbeds are not sufficient anymore for realistic validation, and the scientific community today needs large-scale field deployments working with the same radio spectrum as the commercial networks and capable of supporting new technologies and services. The evolution from lab testbeds to field deployments is required to increase the validation capabilities for complex systems like connected cars, massive Internet of Things (IOT) or eHealth solutions. Appropriate frequency bands, needed by researchers to carry out, for example, large-scale 5G experiments, are generally allocated via auctions and on an exclusive basis to large mobile network operators. 
While it is perfectly feasible for these MNOs to keep dedicated slices for tests and demonstrations in their networks separate from their day-to-day operations without negative effects for the latter, there are few regulatory mechanisms for stimulating MNOs to make parts of their spectrum usage rights available for the academic research community. All EU Member States allow short-term licenses for the use of radio spectrum for research, testing, and experimental purposes, but procedures, requirements, and costs for obtaining such license vary significantly. These national differences do not allow for the creation of a persistent and pan-European network of wireless capacity for research, testing, and experimental purposes. On the secondary market, leasing or transferring radio spectrum usage rights is possible, and procedures seem more harmonized.

For citation: Dumortier J., Bogdanovskaya I.Yu., Vandesande N., Yakushev M.V. Sharing Radio Spectrum for Research and Innovation. Legal Issues in the Digital Age. 2021, no. 4, pp. 34-69. DOI: 10.17323/2713-2749.2021.4.34.69.

\section{Introduction}

Almost every country today ensures easy access for the academic research community to high-performance electronic communications networks and infrastructures. National research networks (so-called NRENs) already interconnected academic institutions long before the Internet existed [Martin O., 2012]. Today one of their main functions is to connect university researchers and students to the Internet. In Europe, the GÉANT network interconnects Europe's NRENs organisations with a pan-European backbone - connecting researchers, academics and students to each other, and linking them to researchers outside Europe, including to the Russian national research networks. The GÉANT network is essential to Europe's e-infrastructure strategy, supporting open science with a future-proof e-infrastructure and advanced networking services for trusted access. In addition, GÉANT allocates dynamically network testbed resources from real e-infrastructure distributed throughout the GÉ ANT core service area, allowing researchers to define, build, test and re build highly scalable, high capacity virtual networks quickly, easily and cost-effectively. GÉANT Testbed Services (GTS) allow users to easily build high performance heterogeneous virtual environments required for their 
experiments. This allows them to focus on the actual experiments and not on the underlying infrastructures necessary to carry out the work. Such flexibility enables rapid prototyping and facilitates early stage innovation in Internet-scale applications and services. Today, NRENs do not provide similar services to the academic research community in the wireless environment. Field trials using mobile networks are mainly hosted by commercial mobile network operators (MNOs), which often do not provide access to the results nor to the infrastructure they have deployed. Yet, due to the growing complexity of mobile networks, the scientific community needs more realistic experimental facilities with the purpose of validating new ideas on networks or services against the expected behaviour. This need is especially critical to study aspects like Quality of Service (QoS) or Quality of Experience (QoE). Research in the context of mobile networks is currently restricted to indoor research platforms built with private or public funding. However, such small-scale testbeds are not appropriate for realistic validation. For instance, they cannot realistically represent a massive number of users in the same radio access point, or thousands of devices for IoT applications, nor take into consideration the complex reality of a real-life deployment. Therefore, the scientific community needs large-scale field deployments working with the same radio spectrum as the commercial networks and capable of supporting the new technologies and services. The evolution from lab testbeds to field deployments is required to increase the validation capabilities for complex systems like connected cars, massive Internet of Things (IoT), or eHealth solutions. In this perspective, the European Commission already supports the aggregation of the experimental facilities, for example interconnecting the current testbeds and field trials. 1 The Future Internet Research and Experimentation (FIRE) objective, put forward in the context of the European Union's multi-annual research programmes, has extended, federated, or even created new research infrastructures for ICT in Europe. ${ }^{2}$ Some of them support wireless cellular communication, but they are basically for indoor deployments, without connection to commercial operators. ${ }^{3}$ Only recently, the European Commission finances feasibility studies for the creation of dedicated wireless service provision for the academic research commun-

${ }^{1}$ Some of these facilities are federated in Fed4FIRE+. Available at: www.fed4fire.eu. (accessed: 22.04. 2020)

2 Available at: https://ec.europa.eu/digital-single-market/en/future-internet-researchand-experimentation(accessed: 22.04. 2020)

3 The same problem has been partially addressed in the USA by the SciWinet initiative. SciWinet works as an umbrella to make agreements easier between universities and MNOs to install new equipment for limited use under a master agreement to share the spectrum. 
ity in large-scale operating mobile networks. These studies show that it is technically possible to share radio spectrum and network infrastructures between commercial mobile network operators and academic researchers without mutual interference or other negative effects. ${ }^{4}$ The problem lies elsewhere, in the readiness of mobile network operators to share their spectrum usage rights and their network infrastructure. This article focuses on spectrum usage rights and the possibilities of sharing such rights from a regulatory point of view. To explain the issue, it is first necessary to understand the basics of radio spectrum regulation.

\section{The Basics of Radio Spectrum Regulation}

\subsection{Characteristics of Radio Waves}

Radio is the transmission of signals by the modulation of electromagnetic waves. These signals go out through the air as radio waves. Radio waves are not directional and travel through space in all directions, like ripples on a pond [Donovan J., 2019]. The frequencies of radio waves vary between $30 \mathrm{~Hz}$ and $3000 \mathrm{GHz}$, corresponding to wavelengths between $10000 \mathrm{~km}$ and $0.1 \mathrm{~mm}$. Radio is particularly suited for wireless communications as it is "easy to use, has good propagation characteristics, and is relatively safe" [Ellingson S.W., 2016]. The history of this technology goes back to the late $19^{\text {th }}$ century, when Heinrich Hertz proved that electricity can be transmitted in electro-magnetic waves.

The radio spectrum is commonly divided into bands. Within a band, channels are typically intended for the same purpose. A band plan will normally determine how the radio frequencies within a particular band can be used, for instance by establishing the bandwidth of each channel within that band, what type of content can be transferred on these channels, who can operate a channel and under which conditions, etc. The aim of the band plan is to avoid interference and to ensure an efficient use of the radio spectrum.

The lowest frequency bands (between $3 \mathrm{~Hz}$ and $3 \mathrm{kHz}$ ) are generally used for (sub)marine communications, as they can penetrate seawater. The highest band is mainly employed in astronomy, although other uses such as for medical imaging - are currently being researched. Typical fre-

${ }^{4}$ One of these studies takes place in the context of the Horizon 2020 research and innovation action "EUWireless" in which two of the authors of this article have been involved. Available at: https://www.euwireless.eu. (accessed: 22.04.2020) 
quencies used by GSM networks are $850 \mathrm{MHz}, 900 \mathrm{MHz}, 1800 \mathrm{MHz}$, and $1900 \mathrm{MHz} .^{5}$

\subsection{Radio Spectrum is a Rival, Non-Excludable Good}

Before delving in the regulation of the radio spectrum, it is useful to determine how the radio spectrum can be considered under the classic economic theory of goods [Samuelson P., 1954]. This theory distinguishes four types of goods, characterized by two criteria: excludability and rivalry. Excludability of a good means that one can block the access of certain people to that good, for instance if those people have not paid for such access. An example here could be any type of consumer electronics, such as laptops. Such device can generally not be obtained unless paid for. Conversely, a vendor could also refuse to make a sale. A non-excludable good is then a good from which access cannot be blocked. An example here is a public landmark, which anyone can see, and which cannot be prohibited from being seen. A rival good is a good that can only be consumed by one person at a time. Bread is a typical example of such rival good, as once a loaf of bread has been consumed, nobody else will be able to consume it. Conversely, a non-rival good can be purchased by several persons at a time. The Internet provides a good example of a non-rival good, as websites can be viewed by many people at the same time. The radio spectrum could be considered as a rival good. While the spectrum cannot be depleted - in the way that an ocean can be depleted from fish due to overfishing - it can become congested by the increasing number of mobile devices using the same frequencies [Herter C., 1985]. This results in interference, which may thus prevent the proper functioning of electronic communications services. While newer technologies exist that may limit this kind of interference, the increasing number of devices using the radio spectrum still results in potential rivalry issues - e.g. the presence of several Wi-Fi routers using the same bands in a small local area.

The radio spectrum could in principle also be considered as a non-excludable good. As radio waves are all around us, it is difficult - if not impossible - to exclude someone from using them. Legislation can be adopted to restrict the use of the radio spectrum, but this does not prevent people from doing so. Even when wireless devices are regulated, it is not

${ }^{5}$ Long-Term Evolution (LTE) or 4G technology is generally deployed on the $700 \mathrm{MHz}$, $800 \mathrm{MHz}, 850 \mathrm{MHz}, 1700 \mathrm{MHz}, 1800 \mathrm{MHz}, 1900 \mathrm{MHz}, 2100 \mathrm{MHz}, 2300 \mathrm{MHz}, 2500 \mathrm{MHz}$, $2600 \mathrm{MHz}$, and $3500 \mathrm{MHz}$ frequencies. 5G technology is expected to use frequencies in the existing LTE range $(600 \mathrm{MHz}-6 \mathrm{GHz})$ and in millimetre wave bands $(24 \mathrm{GHz}-86 \mathrm{GHz})$. Other popular wireless technologies include Bluetooth (operating around $2400 \mathrm{MHz}$ ), NearField Communication (NFC, operating at $13.56 \mathrm{MHz}$ ), and Wi-Fi $(2.4 \mathrm{GHz}$ and $5.8 \mathrm{GHz}$ ). 
unfeasible to obtain or build a receiver for certain wireless communications. Alternative methods - such as the encryption of signals - will have to be used to prevent people from receiving the wireless communication in understandable form.

This rivalrous, yet non-excludable nature of the radio spectrum makes it a common pool resource [Berge E., Kranakis E., 2011]. Such resource, if left unmanaged, could fall victim to what Hardin famously called 'the tragedy of the commons', whereby an unregulated resource could become subject to overuse and overconsumption, thus potentially destroying the resource in the process [Hardin G., 1968]. ${ }^{6}$ For the radio spectrum, such to some extent occurred in the 1920s, when hundreds of new radio stations took the air and used "any frequencies they desired, regardless of the interference thereby caused to others". As a result, "with everybody on the air, nobody could be heard"?

\subsection{Objectives of Spectrum Regulation}

To avoid this kind of tragedy of the commons, some form of regulation of common pool resources may be proposed. One example is Ostrom's model for self-governing commons [Ostrom E., 1990]. In the context of spectrum management, there is a recent movement arguing in favour of true spectrum commons self-regulation [Brito J., 2006]. Nevertheless, most states have adopted the models Ostrom criticized most: state intervention and private property [Rishabh, 2016]. When using state intervention - also called 'command and control' - the state will adopt a legal framework to determine the frequency bands, their specific uses, the technologies to use these bands, and the administrative authorization of users. This approach centralizes the control and legitimizes certain uses of the spectrum. In more recent years, states have been allocating full control over specific bands to private actors using public auctions. This shift from state intervention to private property came following Coase's assertion that private ownership could lead to a more efficient utilization of the radio spectrum [Coase R.M., 1959].

From a regulatory point of view, the radio spectrum could be compared to a beach. While in principle a beach is freely accessible for everyone, it is possible to establish certain ground rules under which the beach can be

${ }^{6}$ The tragedy of the commons refers to a dilemma described in Garrett Hardin's article. He describes a situation in which multiple individuals, acting independently, and solely and rationally consulting their own self-interest, will ultimately destroy a shared limited resource even when it is clear that it is not in anyone's long-term interest for this to happen.

7 National Broadcasting Co. v. United States, 319 U.S. 190 (1943). 
used - e.g. only allowing swimming in designated areas under supervision of lifeguards. However, it is also possible to give (part of) a beach in private concession to a hotel. In such case, that (part of a) beach can only be used by the hotel's guests. Going back to the radio spectrum: while radio waves can in principle be used by anyone, governments have determined the basic rules for utilizing radio communications. Moreover, states have reserved certain sections of the radio spectrum for the exclusive use of the private sector users that are being awarded an operating license hereto.

When regulating the radio spectrum, it is furthermore necessary to adopt an international outlook. This is of course because radio waves do not stop at national borders, and therefore may end up interfering with or even jamming transmissions of another state [Hook C., 1993]. Therefore, while states will use their sovereign rights to regulate the radio spectrum within their own territory, there are also several levels of international cooperation in order to harmonize spectrum allocation and to ensure effective spectrum management.

At the global level, the radio spectrum is regulated by the ITU for its 193 Member States. ${ }^{8}$ At the regional European level, regulation is issued by the European Conference of Postal and Telecommunications Administrations (CEPT) with 48 Member States, including the Russian Federation. ${ }^{9}$ At the EU level, the basic provisions regarding radio spectrum management are laid down in the Electronic Communications Code. ${ }^{10}$ At the lowest level, states can still adopt their own policies and auction parts of the radio spectrum under their sovereign control. National aspects of spectrum regulation include, inter alia, the allocation of frequencies to services, organizing licensing auctions, coordinating with neighbouring countries and international and supranational organizations such as the ITU, CEPT, and the EU.

\subsection{Spectrum Regulation at the International Level}

\subsubsection{International Telecommunication Union}

States have a long history of coordinating the facilitation of international communications. In the $19^{\text {th }}$ century, when the telegraph gained

\footnotetext{
${ }^{8}$ Available at: https://www.itu.int. (accessed: 22.04.2020)

9 Available at: https://cept.org. (accessed: 22.04.2020)

10 Directive (EU) 2018/1972 of the European Parliament and of the Council of 11 December 2018 establishing the European Electronic Communications Code, OJ L321 of 17December 2018.
} 
popularity, states gathered at the 1865 International Telegraph Convention to discuss international telegraph connections and standardization. This convention resulted in the creation of the International Telegraph Union. States agreed that they would continue to manage telegraphy within their own territory but would let the International Telegraph Union manage international telegraphy. In 1885, the International Telegraph Union also started looking into international telephony. Similarly, when later wireless telegraphy gained popularity, states gathered at the International Radiotelegraph Convention in 1906 and established the International Radiotelegraph Union. As can be determined from its name, this organization concerned the international management of radiocommunications. In 1932, these organizations merged to form a single international telecommunication organization, the International Telecommunication Union (ITU). In 1947, the ITU became a specialized agency of the United Nations (UN), headquartered in Geneva, thus operating within the broader UN framework and network.

Membership with voting rights to the ITU is open to all UN Member States. Additionally, any private organization — such as device manufacturers, service providers, or research institutions - can obtain non-voting membership. The ITU also maintains regional and area offices all over the world and works closely with regional institutions, such as the CEPT. In 1992, the ITU was restructured along three sectors: ITU-R for radiocommunication, ITU-T for standardization, and ITU-D for development. Additionally, ITU Telecom organizes global events.

The goal of ITU-R is "to ensure rational, equitable, efficient and economical use of the radio-frequency spectrum by all radio communication services, including those using satellite orbits, and to carry out studies and adopt recommendations on radio communication matters".11 Apart from the ITU Constitution and ITU Convention the main legal instrument regulating the radio spectrum are the Radio Regulations. ${ }^{12}$ This administrative instrument is binding for ITU members.

\subsubsection{Radio Regulations}

The Radio Regulations are adopted at the World Radio communication Conferences (WRC). These conferences are held in principle every

${ }^{11}$ Available at: www.itu.int/en/ITU-R/information/Pages/mission-statement.aspx. (accessed: 22.04. 2020)

${ }^{12}$ International Telecommunication Union. Radio Regulations. 2016. 
four years. ${ }^{13}$ The Radio Regulations distinguish between allocation, allotment, and assignment of radio spectrum. Allocation refers to the division of the radio spectrum into frequency bands. This division is laid down in the Table of Frequency Allocations. Allotment means designating a certain frequency band to a category of radio communication services. The allotment can be for one or more identified countries or geographical areas, and under specific conditions. This means that the allotment of frequencies is not necessarily uniform for the whole world but can differ per region in order to cater to regional needs. Assignment means that an administration - typically at the national level - provides authorization to an entity to use a specific frequency channel under certain conditions. Member States must "limit the number of frequencies and the spectrum used to the minimum essential to provide in a satisfactory manner the necessary services" (article 4(1) Radio Regulations). New assignments must avoid interference with frequencies already assigned according to the Table of Frequency Allocations (article 4(3) Radio Regulations). Member States may, however, conclude special arrangements between each other "regarding the sub-allocation of bands of frequencies to the appropriate services of the participating countries" (article 6 (1) Radio Regulations).

\subsubsection{The Role of the CEPT}

At a Pan-European level, the European Conference of Postal and Telecommunications Administrations (CEPT) was established in 1959. The main goal of the CEPT is to "collaborate to harmonise telecommunication, radio spectrum, and postal regulations to improve efficiency and co-ordination for the benefit of European society" ${ }^{14}$ Initially, the CEPT served as the coordinating body for the national telecommunications and postal state monopolists. However, as these entities gradually became privatized during the 1990s, they have been replaced by the competent policymakers and regulators. As of 2020, CEPT has 48 members, including all EU and EFTA nations, the Balkan countries, the Russian Federation, and Turkey. Within the CEPT, the Electronic Communications Committee (ECC) develops common policies and regulations in electronic communications for Europe and is a focal point for information on spectrum use. Its primary objective is to harmonise the efficient use of the radio spectrum, satellite orbits and num-

13 The most recent World Radiocommunication Conference (WRC-19) took place from 28 October to 22 November 2019 in Sharm el-Sheikh, Egypt.

14 Available at: www.cept.org/files/1047/CEPT\%20Leaflet_June\%202018.pdf. (accessed: 22.04 .2020 ) 
bering resources across Europe. It also prepares common proposals to represent European interests in the ITU and other international organisations. The ECC itself is supported by Working Groups and Project Teams which carry out expert regulatory and technical studies and consultations to inform the ECC's policy, and to create the deliverables which it approves. Two of the ECC's main outputs are "Decisions" and "Recommendations" on major harmonization issues. Many CEPT Decisions relate to the harmonised use of particular frequency bands for designated functions. ${ }^{15}$ CEPT Member States are bound to implement ECC Decisions.

\subsection{Spectrum Management Policy of the European Union}

\subsubsection{EU Radio Spectrum Legislation}

In 2002, the EU adopted the Radio Spectrum Decision, calling for coordination on radio spectrum regulation at the level of the EU. ${ }^{16}$ The goal of the decision was to facilitate the development of an EU radio spectrum policy - in line with policies adopted at the level of CEPT and ITU - and to ensure effective implementation of radio policy. The decision establishes a Radio Spectrum Committee to advise the European Commission on radio spectrum matters. It also created the Radio Spectrum Policy Group (RSPG). ${ }^{17}$ This is a high-level advisory group assisting the Commission in the development of radio spectrum policy, consisting of representatives of the Member States and the European Commission. In doing so, it also takes into account economic, political, cultural, strategic, health, and social considerations, whereas the aforementioned Radio Spectrum Committee is focused more on the technical aspects of spectrum management.

In 2007, the European Commission addressed new market evolutions - such as the growing need for broadband Internet. It therefore proposed amendments to the 2002 framework, which was eventually adopted as the new Telecoms Package in 2009. This package consisted of three texts:

15 See, for example, the ECC Decision of 13 March 2009 on the harmonised use of the 63.72-65.88 GHz frequency band for Intelligent Transport Systems (ITS), amended on 4 March 2016 and amended on 5 July 2019. Available at: https://www.ecodocdb.dk/download/09d84da1-2776/ECCDEC0901.PDF. (accessed: 22.04.2020)

${ }^{16}$ Decision No 676/2002/EC of the European Parliament and of the Council of 7 March 2002 on a regulatory framework for radio spectrum policy in the European Community. OJ L 108 of 24 April 2002.

17 Commission Decision 2002/622/EC of 26 July 2002 establishing a Radio Spectrum Policy Group. OJ L 198 of 27 July 2002. 
a directive amending the Framework, Authorization and Access directives;

a directive amending the Universal Services and E-privacy directives; and

a regulation establishing the Body of European Regulators for Electronic Communications (BEREC).

BEREC, based in Riga, serves as the regulating agency for the telecommunications market in the EU. In this capacity, it advises the European Commission on its telecommunications policies. Its board is composed of representatives of the competent national regulators. BEREC replaces the European Regulators Group for electronic communications networks and services, which was established for similar purposes in 2002.

The 2009 amendments mainly concerned measures to strengthen the internal market, to allow for more flexible management of the radio spectrum, to strengthen consumer protection - including the adoption of net neutrality rules. The package also strengthened the role of the European Commission in relation to national market regulators.

In 2016, the European Commission launched the so-called Connectivity Package. As part of this package, it proposed a single European Electronic Communications Code (EU ECC) holding the EU-wide rules on the regulation of the telecommunications market (European Commission, 2016). Other aspects of the package include common broadband targets for 2015, a 5G Action Plan, and a voucher scheme to offer free Wi-Fi access to citizens. ${ }^{18}$

The European Electronic Communications Code was adopted in 2018. ${ }^{19}$ It reaffirms that Member States may not prevent an undertaking from providing electronic communications networks or services, unless necessary (article 12(1]), although notification requirements can be implemented, as well as certain conditions (article 13(1)).

Undertakings derive a minimum of rights from the principle of general authorization, such as the right to provide electronic communications services and to use the radio spectrum in doing so (article 15(1)). They may, however, be subjected to administrative charges (article 16(1)). When existing rights get restricted or withdrawn, due compensation is needed (article 19(1)).

18 Available at: https://ec.europa.eu/digital-single-market/en/policies/improving-connectivity-and-access. (accessed: 22.04.2020)

19 Directive (EU) 2018/1972 of the European Parliament and of the Council of 11 December 2018 establishing the European Electronic Communications Code, OJ L 321 of 17 December 2018. 
Member States will continue to coordinate their radio spectrum use, to avoid harmful cross-border interference (article 28(1)). A peer review process is established for when Member States undertake a selection procedure (article 35(2)). In the case of a harmonized spectrum band, when access conditions and procedures have been imposed, and undertakings to which the radio frequencies spectrum was assigned have been selected in accordance with applicable rules, Member States must grant the right of use for such radio frequencies spectrum in accordance with those rules (article 36). Fees can be levied for the right to use the radio spectrum (article $42(1))$.

Member States will still ensure access to the radio spectrum in accordance with objective, transparent, procompetitive, non-discriminatory, and proportionate criteria, as well as in respect of international agreements (Article 45(1)). Still, the EU legislator remains principally neutral toward the type of services provided or the technology used (Article 45(4)-(5)). While general authorization remains the basic principle, Member States can still resort to limited or individual authorizations in certain cases (article 46(1)). The use of the spectrum may be subjected to conditions (article 47(1)). Individual rights must be awarded for a certain period of time, ensuring "regulatory predictability for the right holders over a period of at least 20 years regarding investment conditions in infrastructure which relies on the use of such radio spectrum" (article 49(1)-(2)). Individual rights can be renewed (article 50(1)) or transferred and leased (article $51(1)$ ).

The EU-ECC also coordinates the timing for the assignment of the $5 \mathrm{G}$ bands, making the $3.4-3.8 \mathrm{GHz}$ and the $24.25-27.5 \mathrm{GHz}$ frequency bands available by the end of 2020 (Article 53a (1)). Where needed, Member States can limit the number of rights granted to part of the spectrum by means of a competitive or comparative selection procedure, "giving due weight to the need to fulfil national and internal market objectives" (Article 54(1) \& 54(2)).

\subsubsection{EU Radio Spectrum Policy Programme}

Apart from the legal framework in the strict sense, the EU has adopted a Radio Spectrum Policy Programme (RSPP) in $2012 .{ }^{20}$ The goal of the RSPP

${ }^{20}$ Decision No 243/2012/EU of the European Parliament and of the Council of 14 March 2012 establishing a multiannual radio spectrum policy programme, OJ L 81 of 21 March 2012. 
is to provide a roadmap for the development of the internal market for wireless technologies and services. Regulatory principles, policy objectives, and priorities can all be found in the program, which aims to enhance efficient and flexible spectrum use, in order to strengthen competition within that market.

The EU also recognizes that additional spectrum might be needed by sectors such as transport research and development $(\mathrm{R} \& \mathrm{D})$, as well as the need to ensure adequate protection against harmful interference to sustain R\&D and scientific activities (recital 29 RSPP). It further states that "Member States and the Commission shall collaborate with the scientific and academic community to identify a number of research and development initiatives and innovative applications that may have a major socio-economic impact and/or potential for investment and consider the spectrum needs of such applications and, where necessary, consider the allocation of sufficient spectrum to such applications under harmonised technical conditions and with the least onerous administrative burden" (article 8 RSPP).

A number of actions taken under this program include:

the identification of $1200 \mathrm{MHz}$ of spectrum for increasing wireless data traffic demands;

allowing spectrum trading throughout the EU in harmonized bands;

fostering different modes of spectrum sharing in the EU;

analysing the efficiency of spectrum use in the $400 \mathrm{MHz}-6 \mathrm{GHz}$ range.

Furthermore, Member States must authorize certain bands that have been reallocated for high speed electronic communications services, more precisely the harmonized $900-1800 \mathrm{MHz}, 2.5-2.69 \mathrm{GHz}$, and $3.4-3.8 \mathrm{GHz}$ bands, as well as the $800 \mathrm{MHz}$ band to cover sparsely populated areas.

\subsection{National Spectrum Management}

\subsubsection{National Competences}

While many aspects of spectrum regulation are regulated at the international, regional, or supranational level, national governments and regulators still have significant competences in this matter and thus remain the main regulator of the radio spectrum. As part of this work, national authorities will have to develop a national allocation table. While a sovereign state is in principle not bound to follow the ITU's regional allocation table exactly, it is of course wise to do so in order to ensure maximal har- 
monization and minimal interference. Moreover, in doing so the national allocation table translates the international and regional allocations into national law.

The national authorities will also determine how to regulate the use of the spectrum. Here, several options are available. In broad strokes, these can be divided between general authorizations and individual authorizations. $^{21}$

In a general authorization, use of the spectrum - or at least of certain bands of the spectrum - will principally be exempt from licensing. This means that in principle no individual license must be obtained in order to use (part of) the radio spectrum. Use of this (part of) the spectrum must therefore also not be notified. This is a model that is often used for consumer-grade devices, such as mobile phones, short-range devices, and amateur radio. Nevertheless, certain rules may still apply, for instance regarding device standards. A particular band may also be designated as a common, meaning that in principle every user and every device can use this band [Medeisis, 2011]. Also here, some general rules may apply, for instance to contain possible interference. For authorities, this model limits their administrative overhead, and the need for coordinating the use of the radio spectrum. For individuals and industry, this model allows for easy and cheap deployment of radio-frequency devices. The main drawback is of course that this may result in uncontrolled use of (that part of) the spectrum, leading to unmanageable interference.

At the other end of the spectrum, there are individual authorizations. Here, use of (part of) the radio spectrum becomes reserved exclusively to those that obtained an individual license. Licenses are generally non-transferable, and subject to regular - generally annual - renewal. Moreover, such licenses are generally subject to fees, to cover the costs incurred by authorities. The main benefit of this model is that it provides the highest degree of security and protection against harmful interference. However, this of course limits the use of the radio spectrum for the broader public, and it requires authorities to organize a - often administratively complex and costly - licensing procedure. There are different ways to grant a license.

One model used in Europe, and particularly in the telecom sector, is that of the auction. In an auction, the competent authority will allow for competitive bidding to gain a license, and only the highest bidder will re-

${ }^{21}$ ECC (2009) Light licensing, license-exempt and commons. Available at: https://www. ecodocdb.dk/download/87ccb237-fa9a/ECCREP132.PDF (accessed: 22.04.2020). 
ceive a license for the auctioned part of the spectrum [Cave E., Nichols R., 2017]. While bidding is in principle open, authorities can set minimum requirements with which interested entities need to comply. The main benefit of this is that it is a fairly simple mechanism, with the propensity of being beneficial for the treasury. While an auction does principally operate in a free market, it is clear that only the larger and wealthier companies can afford such bid. While this model therefore in principle leaves the matter open to the market, it could also be argued that it enables those with a dominant market position to further entrench themselves [Beltrán F., 2016].

Licenses can also be awarded on a 'first come, first served' basis. In this case, frequencies are awarded in order of application, subject to availability. While this is an oft-used model, there are a few drawbacks. For one, this model only works if the frequencies involved are not too scarce. Moreover, there is little certainty that the entity to which the license is awarded will indeed use that license efficiently. This is, in part, because such model encourages entities to submit an application as early as possible, even if they do not intend to immediately utilize the license.

Other means of awarding licenses include lotteries and beauty contests. The former relies on chance, the latter generally includes a public procurement procedure in which the competent authorities set a number of criteria - possibly with a particular weight attached to each criterion - from which the entity best corresponding to those criteria is selected. Of course, organizing such lottery or beauty contest is a more complicated procedure than that of the auction. In some cases, a more simplified procedure can be envisioned for a more limited number of users, which already leans more to the following model, but still with characteristics of the individual license.

A model in between these options is that of light-licensing. Here, the use of (part of) the radio spectrum is subject to registration. Upon that registration, an interference check is performed to determine whether the intended use would interfere with previous registrations, thus working on a 'first come, first served' basis. Since this process can be fully automated, it requires little to no input from authorities. At the same time, the registration duty allows for the control and limitation of the radio spectrum use and allows for authorities to collect a fee as means of incentive pricing. It is therefore a suitable method for services with a high and fluid demand, such as amateur radio and ship radio licenses.

These models can be summarized as follows. 


\section{Authorization overview ${ }^{22}$}

\begin{tabular}{|l|l|l|l|}
\hline \multicolumn{2}{|c|}{$\begin{array}{l}\text { Individual authorisation } \\
\text { (Individual rights of use) }\end{array}$} & \multicolumn{2}{c|}{$\begin{array}{c}\text { General authorisation } \\
\text { (No individual rights of use) }\end{array}$} \\
\hline $\begin{array}{l}\text { Individual licence } \\
\text { Light-licensing } \\
\text { quency planning / } \\
\text { coordination }\end{array}$ & $\begin{array}{l}\text { Individual fre- } \\
\text { quency planning / } \\
\text { coordination }\end{array}$ & $\begin{array}{l}\text { No individual fre- } \\
\text { quency planning / } \\
\text { coordination }\end{array}$ & $\begin{array}{l}\text { No individual fre- } \\
\text { quency planning / } \\
\text { coordination }\end{array}$ \\
$\begin{array}{l}\text { Traditional pro- } \\
\text { cedure for issuing } \\
\text { licenses }\end{array}$ & $\begin{array}{l}\text { Simplified proce- } \\
\text { dure compared to } \\
\text { traditional proce- } \\
\text { dure for issuing } \\
\text { licenses }\end{array}$ & $\begin{array}{l}\text { Registration and/ } \\
\text { or notification }\end{array}$ & $\begin{array}{l}\text { No registration } \\
\text { nor notification } \\
\text { in the number of } \\
\text { users nor need for } \\
\text { coordination }\end{array}$ \\
\hline $\begin{array}{l}\text { With limitations } \\
\text { in the number of } \\
\text { users }\end{array}$ & \\
\hline
\end{tabular}

\subsubsection{Spectrum Management in the Russian Federation}

In Russia the regulation of the use of the radio frequency spectrum is the exclusive right of the Federal State. The Federal law "On Communication" is the basic legislative act in this domain. ${ }^{23}$

Radio regulations are issued by the State Commission on Frequency Management. A guide published by the State Commission includes the Russian Federation table of frequency allocations in the frequency range $3 \mathrm{KHz}$ to $400 \mathrm{GHz}$, policies on allotment and monitoring of frequency usage, regulations on the production, purchase, import and use of radio equipment, a copy of the legislation relating to wireless and broadcast licensing, information on the certification of radio equipment and a list of the basic EMC standards and technical requirements.

The Government of the Russian Federation establishes the powers of the state executive body, defines the list of radio-electronic means and high-frequency devices, subject to registration, approves a Table of frequency allocations, plans prospective use of radio frequency spectrum, and

${ }^{22}$ ECC (2009) Light licensing, license-exempt and commons. Available at: https:// www.ecodocdb.dk/download/87ccb237-fa9a/ECCREP132.PDF (accessed: 22.04.2020)

${ }^{23}$ Federal law of 7 July 2003 (with amendments of 02.07.2021) "On Communication", Art. 22. // SPS CjnsiltantPlus 
fixes the charges for use of the radio frequency spectrum, its collection, distribution and use. The Ministry of the Digital Development, Communications and Mass Media of the Russian Federation elaborates the policy, realizes law-making power, appoints a radio frequency or radio frequency channel for radio-electronic means for civil purposes, permits forced changes of a radio frequency or a radio frequency channel in exceptional cases and licenses the provision of electronic communications services. ${ }^{24}$

Licences to use the radio spectrum are issued for a term from three years to 25 years, taking into account the period specified in the application, the nature of the communications service and the period specified by the State Commission for the requested frequency band. In accordance with its Federal laws and Government decrees, the Russian Federation requires a one-time initial payment and an annual fee for use of its radio frequency spectrum.

\section{Access to Radio Spectrum for Research Purposes}

\subsection{Temporary Spectrum Licensing for Testing and Demonstration}

Key players in the telecom sector have called upon the European Commission and Member States to "encourage and incentivize cross-sector innovation through adequate policies and support for cross-sector hubs for experiments, trials and large-scale pilot programs". Moreover, in its roadmap for pan-European $5 \mathrm{G}$ trials, the $5 \mathrm{G}$ Infrastructure Association has called for a specific joint strategy between industry, research centres, academics, local communities, public authorities and domain-specific initiatives (5G Infrastructure Organization, 2016). Experimental hubs, trials and pilots usually work with radio spectrum obtained on a temporary basis for testing and demonstration on a particular location. Procedures for granting such temporary licenses for testing and demonstrations exist in most countries.

In France, for example, applications for radio spectrum for experimental use must be addressed to the Autorite de Régulation des Communications électroniques et des Postes (Arcep). ${ }^{25}$ Experimental use in this context is the use of the radio spectrum for the technical or commercial development of a novel technology or service whereby the turnover and number of users

\footnotetext{
${ }^{24}$ Order of the President of RF of 5 May 2018 №215 // SPS ConsiltantPlus.

${ }^{25}$ Article L42-1(IV) of the Code des postes et des communications électroniques.
} 
of that technology or service remain below a certain threshold during the experiment. This threshold has been set at a turnover of EUR 500.000 and a number of users of 2.500 (D406-17-1 Code des Postes et des Communications électroniques). Applications must describe the frequency bands that will be used, the desired and minimal bandwidth, the location and duration of the experiment, and the test set-up. A more detailed technical description will list the technology and service type, the characteristics of any fixed stations used, and the overall technical and operational architecture. Applications may be filed only by legal persons and their representatives. Licenses can be granted for a maximum of two years. The fees owed for the assignment of a temporary license are calculated by means of a complex formula determined by law. ${ }^{26}$

In Germany, the competent authority is the Bundesnetzagentur, with competences over the telecommunications, postal, railway, and energy markets. ${ }^{27}$ According to article 55(1) of the German Telecommunications Act, every usage of the radio spectrum requires an assignment by the Bundesnetzagentur. ${ }^{28}$ However, individual deviations from the frequency plan may be justified for testing innovative technologies in telecommunications, or in the event of short-term frequency requirements. Article 58(2) of the German Telecommunications Act therefore allows for temporary licenses to be issued. Such temporary licenses, however, may not hinder pre-assigned frequency use. Applications can be submitted through e-mail. Information to be provided includes the contact information of the applicant, a description of the use including its geographical coverage and time of use, information about the devices, the desired frequency and bandwidth, the antenna's used, and a description of the frequency use. Applications can be filed by natural and legal persons. They must be filed at least four weeks before the intended usage. An EUR 130 fee is levied for temporary licenses per channel, with an additional EUR 50 per channel. Temporary licenses can be issued for up to maximum 30 days, subject to possible extension up to three consecutive months.

${ }^{26}$ Décret $n^{\circ} 2007-1532$ du 24 octobre 2007 relatif aux redevances d'utilisation des fréquences radioélectriques dues par les titulaires d'autorisations d'utilisation de fréquences délivrées par l'Autorité de régulation des communications électroniques et des postes \& Arrêté du 24 octobre 2007 portant application du décret n²007-1532 du 24 octobre 2007 relatif aux redevances d'utilisation des fréquences radioélectriques dues par les titulaires d'autorisations d'utilisation de fréquences délivrées par l'Autorité de régulation des communications électroniques et des postes.

27 Available at :https://www.bundesnetzagentur.de. (accessed : 22.04.2020)

28 Available at : https://www.gesetze-im-internet.de/tkg_2004/. (accessed: 22.04.2020) 
In the United Kingdom, non-operational licenses can be obtained to use the radio spectrum to promote the development and trials of innovative uses of the radio spectrum. Such licenses allow for the testing and development of wireless radio equipment, scientific research and experimentation, and for trials and demonstrations of radio apparatus. Commercial or operational usage is not permitted. Furthermore, these licenses are awarded on a non-interference and non-protection basis. Application can be made through a form provided by Ofcom. ${ }^{29}$ Ofcom distinguishes between Innovation and Research licenses - used for research, development and testing purposes - and Demonstration and Trial licenses largely used for demonstrating and testing new equipment. ${ }^{30}$ Innovation and Research licenses allow the use of spectrum on a non-commercial, non-permanent basis in order to build innovative spectrum apparatus or equipment, or to undertake academic or scientific research. Such license also covers the testing of equipment for various purposes. It only allows for the use of spectrum at a single location, such as a university, test facility, factory or laboratory. Involvement of the public is not allowed, but certain collaboration and testing work with third parties is permitted insofar this does not constitute an operational service. A Demonstration and Trial license allows for the use of spectrum on a non-commercial, non-permanent basis to trial and demonstrate a new system, radio concept, application or service. The involvement of third parties in trials is allowed, provided that participants are fully informed on the nature of the trial. Demonstration and Trial licenses can only be obtained for new services not fitting within existing license categories. Both licenses can be awarded for a period of up to one year. While renewal is not possible, a new license can be obtained for further research and trials. Applications can be submitted by both legal and natural persons. Applications must provide information on the project's location and time scale, a description of Costs of these licenses are GBP 50 per year and per location for an Innovation and Research license, and GBP 50 per month and per location for a Demonstration and Trial license [Ofcom, 2018].

In Russia, the overall mechanism for allocation of radio frequency bands for conducting R\&D and testing new technological solutions does not differ much from the general procedures established by the Russian State Committee for Radio Frequencies (SCRF). The Regulation regarding

${ }^{29}$ Available at: www.ofcom.org.uk/_data/assets/pdf_file/0023/80780/application_form_ ofw225.pdf. (accessed: 22.04.2020)

${ }_{30}$ Available at: https://www.ofcom.org.uk/manage-your-licence/radiocommunicationlicences/non-operational-licences. (accessed: 22.04.2020) 
the State Committee $(\$ 15)$ allows the latter to make decisions related to the allocation of a selected radio spectrum band (or bands) for a specific person (individual or legal entity), with the purpose to conduct scientific, research, experimental and design activities, for a period necessary to perform these activities. In principle every individual can apply for such a license, by submitting a standardised form including an explanatory note with details on the purpose of the trial, the requested frequency band, the geographical location, technical specifications on the radio equipment that will be used, etc. The application will be registered by the SCRF administration within one working day. ${ }^{31}$ The SCRF Administration processes the application ("preliminary analysis") within 10 working days from the date of its registration (Section 15 of the Procedure for allocating radio frequency bands). Within five working days after the preliminary analysis (i.e. approximately three weeks after the reception of the application), the SCRF sends a letter indicating the need to examine the possibility of using the requested radio frequency band in the indicated region and (or) in the territory of the Russian Federation, with the attached Radio Frequency Application materials to (a) the Ministry of Defence of the Russian Federation, (b) the Federal Service for Supervision in Telecommunications, Information Technologies and Mass Communications ("Roskomnadzor"), (c) the Federal Protection Service of Russia (FSO), for the clearance on allocating the requested radio frequency band(s). A similar letter will also be sent to other federal agencies, if these agencies could be affected by the temporary license (Section 17 of the Procedure for allocating radio frequency bands). These administrations concerned have approximately six weeks (30 working days) to prepare their opinions on the possibility of allocating the requested radio frequency band(s) and send the opinions (on paper or electronically) to the SCRF Administration (Section 21 of the Procedure for allocating radio frequency bands). Based on the received feedback (clearance or refusal), the SCRF Administration, within 10 working days, prepares a draft decision of the SCRF for further approval by the Commission.

If within a term of processing of the Application, the need for additional technical tests (to assess the electromagnetic compatibility etc.) appears, the Commission makes the decision to extend the processing of the application based on the substantiated justification of the concerned member

${ }^{31}$ Processing of the Applications is organized by the SCRF Administration in accordance with the Regulations of the SCRF and the "Procedure for reviewing materials and making decisions on the allocation of radio frequency bands, re-issuing and amending decisions", approved by the Decision of the SCRF of December 20, 2011. No 11-13-01. 
of the SCRF. Such extension may be made only once and for the period not more than six months (Section 21 of the Procedure for allocating radio frequency bands).

Decisions of the SCRF are taken by a simple majority of votes of members of the Commission by open vote, taking into account written opinions of members of the Commission. In case of equality of votes (tie), the vote of the Chairperson of the meeting prevails. All decisions are published on the official website of the Ministry of the Telecommunications. Particular decisions on allocation of radio frequencies to a specific person are sent to the applicant in the form of an extract from the Decision of the SCRF.

\section{Access to spectrum via spectrum trading or leasing}

Temporary spectrum usage licenses for the testing and development of wireless radio equipment, scientific research and experimentation, and for trials and demonstrations of radio apparatus, are typically suited for operating limited testbeds. As already emphasized before, there is currently also a need to test innovative solutions on the large-scale operational networks of the MNOs. Theoretically, this could be solved by granting usage rights in the same frequency band to multiple users, whereby every user makes use of technologies to dynamically share the radio spectrum without mutual interference.

\subsection{Access to spectrum via (dynamic) spectrum sharing}

Dynamic spectrum sharing techniques have been developed in order to answer the need for better utilization of the spectrum resources. In the following, an overview is provided of the spectrum sharing principles and the regulatory status of different spectrum sharing methods in Europe and USA.

\subsubsection{Spectrum sharing overview}

Currently, cellular mobile communications networks, such as 2G, 3G and $4 \mathrm{G}$, are typically deployed by a small number of MNOs. These deployments are based on individual access rights that are acquired through auctions organized by national regulatory authorities. Usually, these access rights cover wide geographical areas and are granted for long-term use and give the MNO exclusive access to the spectrum band [Cramton P., 2013]; [Olla P., Patel N., 2002]; [Feasey R., 2015]. On the other hand, the bands that have not been allocated to the mobile communications are usually 
licensed for other use, such as TV broadcasting or terrestrial-satellite communications.

As it is challenging to clear spectrum bands from incumbent usage, sharing-based spectrum governance models have become increasingly appealing for NRAs to allow new entrants to use otherwise underutilized spectrum bands in a timely manner [Anker P., 2017]; [Beltran G., 2017]. This has led to the development of spectrum sharing mechanisms where two or more wireless systems operate in the same spectrum band [ITU, 2014; RSPG, 2011; RSPG, 2013]; [Matinmikko-Blue M., 2018]. Spectrum sharing methods can be categorized according to licensing and authorization into individual authorization, light licensing and license-exempt access.

The currently dominating spectrum licensing scheme is dedicated access, one of the individual authorization methods. In individual authorization the MNO, or another spectrum user such as a satellite system, is granted an exclusive right to utilize the spectrum band. Co-primary shared access falls also under individual authorization. Under this scheme, the license holders use their licenced spectrum jointly in a shared manner through mutual agreements, subject to the permission of the competent authority. The participating MNOs have equal access rights to the spectrum, without priorities set by the authority.

Licensed shared access (LSA) and authorized shared access (ASA) also belong under the individual authorization regime. Although ASA and LSA essentially refer to same paradigm, ASA can be seen as a special case of LSA where the licensee is an MNO, while in LSA the licensee can also be another type of entity. However, in both ASA and LSA, a non-mobile communication license holder, referred to as incumbent, can share spectrum with one or more mobile communications systems under certain rules and in non-interfering basis.

The term light licensing refers to a simplified and more flexible regulatory framework of issuing spectrum authorizations compared to fully exclusive authorization, usually targeted to the frequency bands where the risk of interference is low [Dahlberg C. et al., 2013]. Example target bands considered reasonable for this access method are $60 \mathrm{GHz}$ and $80 \mathrm{GHz}$ bands, whose propagation characteristics facilitate the use with minimum risk of interference.

License-exempt access or unlicensed access refers to a scheme where a set of users co-exist and are able to utilize a specific frequency bands opportunistically with equal priority rights. The bands can range from li- 
censed to unlicensed bands such as narrowband licensed television white space (TVWS) and Wi-Fi bands in $5 \mathrm{GHz}$. However, the users operating on this licensing regime must comply with the general technical regulations defined for the bands and be certified.

\subsubsection{Regulatory concepts for spectrum sharing}

\subsubsection{Europe: $L S A$ and $A S A$}

LSA was introduced as a general concept to facilitate controlled sharing between any two systems in such way that predictable QoS is provided. ${ }^{32}$ The RSPG provided an opinion on this matter in which it defines LSA as "a regulatory approach aiming to facilitate the introduction of radio communication systems operated by a limited number of licensees under an individual licensing regime in a frequency band already assigned or expected to be assigned to one or more incumbent users. Under the Licensed Shared Access (LSA) approach, the additional users are authorised to use the spectrum (or part of the spectrum) in accordance with sharing rules included in their rights of use of spectrum, thereby allowing all the authorized users, including incumbents, to provide a certain Quality of Service (QoS)" ${ }^{33}$ LSA is therefore not a new licensing regime, but a complementary spectrum management tool that allows multiple individual licensees to each have exclusive individual access to a portion of spectrum at a given location and time. Harmonized usage conditions would need to ensure a smooth coordination between incumbent licensees and new licensees allowed under the LSA regime.

The first regulatory report from the CEPT on LSA provided an overall description of the LSA concept as a general regulatory framework and its applicability to the current regulatory practices regarding spectrum use. ${ }^{34}$ The EU then gave a Mandate to the CEPT to study harmonized conditions for mobile use regarding the $2.3-2.4 \mathrm{GHz}$ band. As a response, the guidelines for the sharing framework for LSA for this band were developed by the CEPT. ${ }^{35}$ First, regulatory and technological options for sharing be-

${ }^{32}$ RSPG (2011). Report on collective use of spectrum (CUS) and other sharing approaches.

33 RSPG (2013). Opinion on licensed shared access. RSPG13-538.

${ }^{34}$ ECC. Report 205: Licensed Shared Access (LSA). Available at: https://www.ecodocdb.dk/download/baa4087d-e404/ECCREP205.PDF (accessed: 22.04.2020)

${ }^{35}$ ECC. Decision (14) 02: Harmonized technical and regulatory conditions for the use of the band 2300-2400 MHz for Mobile/Fixed Communications Networks (MFCN). 
tween mobile broadband and the relevant incumbent services were identified. This included an overview of different incumbent services on the band in all European countries and options for sharing for each of these services. ${ }^{36}$ The incumbent services are Programme Making and Special Events (PMSE), telemetry, fixed links, and Unmanned Aircraft Systems (UAS). There is also an amateur service on a secondary basis, but it does not need to be protected in the same way as other incumbent services. Second, a more detailed study on the technical sharing solutions between the mobile broadband and PMSE was given. ${ }^{37}$ In this study, a step-bystep approach for the implementation of an LSA sharing framework was introduced with the following steps: determining the extent and type of incumbent use, calculating the protection criteria for the incumbent, and identifying operational conditions for sharing, such as implications for the mobile network.

Shared use of the radio spectrum has also been included in the EUECC, which specifically mentions the possibility of LSA (Article 2 (26) EU-ECC). Articles 45(2) and 46 of the EU-ECC require Member States to promote and set the conditions for the shared use of the radio spectrum, in accordance with competition law.

\subsubsection{European TV white spaces}

Television white space (TVWS) equipment operates in the unused frequency gaps between high power television broadcast stations The European regulatory activities on TVWSs were initiated in the ECC of CEPT by addressing technical and operational requirements for the possible operation of cognitive radio systems in the white spaces in order to protect the incumbent radio services from the harmful interference. ${ }^{38}$ The work was

https://www.ecodocdb.dk/download/b02d6dab-2b58/ECCDEC1402.PDF (accessed: 22.04.2020)

${ }^{36}$ CEPT (2015) Report 56: Technological and regulatory options facilitating sharing between wireless broadband applications (WBB) and the relevant incumbent services/applications in the $2.3 \mathrm{GHz}$ band. Available at: https://www.ecodocdb.dk/download/16fde9f89f82/CEPTREP056.PDF. (accessed: 22.04.2020)

37 CEPT (2015) Report 58: Technical sharing solutions for the shared use of the 2300$2400 \mathrm{MHz}$ band for WBB and PMSE. https://www.ecodocdb.dk/document/related/58. (accessed: 22.04 .2020$)$

38 ECC (2011) Report 159: Technical and operational requirements for the possible operation of cognitive radio systems in the white spaces of the frequency band 470-790 MHz. Available at: https://www.ecodocdb.dk/download/be051b35-91e9/ECCREP159. PDF (accessed: 22.04.2020) 
continued with technical investigations for the development of the regulation for white space devices. ${ }^{39} \mathrm{Next}$, the use of centralized geo-location databases for protection of the incumbent services, including framework proposals and feasibility assessment, was provided. ${ }^{40}$ Finally, ECC introduced the overall framework for TVWS devices using geolocation databases and for providing guidance for national implementation, including options for database policy and provision. ${ }^{41}$

\subsection{European regulatory framework for spectrum sharing}

\subsubsection{EU Telecommunications framework}

As noted before, the European legislator in the 2009 overhaul of its telecoms package decided to open up the possibility for a secondary radio spectrum market to develop. This was the result of the insertion of a new provision, Article 9b, by the so-called Better Regulation Directive ${ }^{42}$ into the former Framework Directive. ${ }^{43}$

The Article 9b of the amended Framework Directive allowed for the transfer or lease of individual rights to use radio frequencies. It established the basic principle that Member States must allow undertakings to transfer or lease to other undertakings their individual rights to use radio frequencies. Such transfer must be in accordance with the conditions attached to

39 ECC (2013) Report 185: Complementary Report to ECC Report 159. Further definition of technical and operational requirements for the operation of white space devices in the band 470-790 MHz. https://www.ecodocdb.dk/document/related/292 (accessed: 22.04.2020)

40 ECC (2013) Report 186: Technical and operational requirements for the operation of white space devices under geo-location approach. European Conference of Postal and Telecommunications Administrations. Available at: https://www.ecodocdb.dk/document/293 (accessed: 22.04.2020)

${ }^{41}$ ECC (2015) Report 236: Guidance for national implementation of a regulatory framework for TV WSD using geo-location databases. Available at: https://www.ecodocdb. $\mathrm{dk} /$ document/related/342 (accessed: 22.04. 2020)

${ }^{42}$ Directive 2009/140/EC of the European Parliament and of the Council of 25 November 2009 amending Directives 2002/21/EC on a common regulatory framework for electronic communications networks and services, 2002/19/EC on access to, and interconnection of, electronic communications networks and associated facilities, and 2002/20/ EC on the authorisation of electronic communications networks and services, OJ L 337 of 18 December 2009.

43 Directive 2002/21/EC of the European Parliament and of the Council of 7 March 2002 on a common regulatory framework for electronic communications networks and services (Framework Directive), OJ L 108 of 24 April 2002. 
their rights of use of radio frequencies and in accordance with national procedures.

Moreover, the amendment allowed transfers within the bands for which this is provided by the implementing measures adopted by the European Commission, which did not cover frequencies used for broadcasting. Member States could allow undertakings to transfer or lease their individual rights to use radio frequencies in other bands as well, in accordance with national procedures.

Any conditions that were imposed on individual right holders to use radio frequencies continued to apply after the transfer or lease, unless otherwise specified by the competent national authority. A waiver to this could be granted by the Member States for the cases where the undertaking's individual right to use radio frequencies was initially obtained free of charge.

Any undertaking's intention to transfer its rights to use radio frequencies, as well as the effective transfer thereof, had to be notified in accordance with national procedures to the competent national authority responsible for granting individual rights of use, and be made public. Where a harmonization of radio frequency use was involved, any transfer had to comply with that harmonized use.

\subsubsection{EU-ECC}

The EU Electronic Communications Code (EU-ECC) adopted in 2018 maintains the principles of the previous provision in its Article 51, albeit in a somewhat altered form. ${ }^{44}$ The EU-ECC states that Member States must ensure that undertakings may transfer or lease to other undertakings their individual rights of use for radio spectrum. In such case, the original conditions attached to the rights of use are maintained. They may still allow a waiver of the procedure where the undertaking's individual right to use radio spectrum was initially obtained free of charge or assigned for broadcasting.

An undertaking's intention to transfer or lease rights of use for radio spectrum, as well as the effective transfer thereof, must still be notified in accordance with national procedures to the competent authority, and be

${ }_{44}$ Directive (EU) 2018/1972 of the European Parliament and of the Council of 11 December 2018 establishing the European Electronic Communications Code, OJ L 321 of 17 December 2018. 
made public. Also here, when there is harmonization, any transfer must comply with such harmonized use.

New in the EU-ECC is that, to prevent a distortion of competition, Member States must submit transfers and leases to the least onerous procedure possible. They may not refuse the lease of rights of use for radio spectrum where the lessor undertakes to remain liable for meeting the original conditions attached to the rights of use, and they may not refuse the transfer of rights of use for radio spectrum unless there is a clear risk that the new holder is unable to meet the original conditions for the right of use. However, this does not diminish the competence of Member States to enforce compliance with the conditions attached to the rights of use at any time, both with regard to the lessor and the lessee, and in accordance with national law.

The transfer or lease of rights of use for radio spectrum must be facilitated by competent authorities by giving timely consideration to any request to adapt the conditions attached to the right, and by ensuring that the rights or the radio spectrum attached thereto may to the best extent be partitioned or disaggregated. Administrative charges imposed on undertakings in connection to processing an application for the transfer or lease of rights of use for radio spectrum may only cover the administrative costs incurred in the management, control, and enforcement of the authorization scheme.

Relevant details relating to tradable individual rights must be made publicly available in a standardized electronic format when the rights are created and must be maintained as long as the rights exist. The European Commission can adopt implementing measures to identify such relevant details.

\subsubsection{Implementation of trading and leasing}

\subsubsection{Implementing measures}

The goal of the European legislator is to facilitate flexibility and efficiency on the spectrum market, and to allow spectrum valuation by the market. ${ }^{45}$ Such would need to lead to more effective spectrum use, while

${ }^{45}$ Recital 132 of the EU Electronic Communications Code: "Transfer of rights of use for radio spectrum can be an effective means of increasing the efficient use of spectrum. For the sake of flexibility and efficiency, and to allow valuation of radio spectrum by the market, Member States should by default allow radio spectrum users to transfer or lease 
still allowing national regulatory authorities to take action in preventing a distortion of competition where spectrum is left unused.

In 2011, the ECC published a report on the spectrum trading practices of CEPT countries. ${ }^{46}$ At the time, a significant discrepancy between EU Member States was found regarding the possibilities for trading or leasing radio spectrum rights of use. This discrepancy can be explained in the sense that several Member States were still busy transposing the 2009 overhaul of the EU telecoms package.

The implementing measures referenced in the amended Framework Directive were adopted as part of the aforementioned Radio Spectrum Policy Programme. ${ }^{47}$ The RSPP determines that Member States must apply technology and service neutrality in the rights of use of radio spectrum for electronic communications networks and services and the transfer or lease of individual rights of use of radio frequencies (article 2(2) (a) RSPP).

More importantly, it is determined that Member States must allow the transfer or leasing of rights of use of spectrum in the harmonized bands of 790-862 MHz, 880-915 MHz, 925-960 MHz, 1710-1785 MHz, $1805-1880$ MHz, 1900-1980 MHz, 2010-2025 MHz, 2110-2170 MHz, 2.5-2.69 GHz, and 3.4-3.8 GHz (article 6(8) RSPP). A later decision added that, when granting rights of use in the $470-790 \mathrm{MHz}$ frequency band for terrestrial systems capable of providing wireless broadband electronic communications services, Member States must allow the transfer or leasing of such rights in accordance with open and transparent procedures pursuant to the applicable Union law (article 2 Decision (EU) 2017/899)..$^{48}$

The RSPP was to be applied by the Member States by 1 July 2015. As a result, trading or leasing rights of use in the harmonized bands mentioned in the previous paragraph should now be possible across the EU. Individual Member States may additionally allow transferring or leasing in other

their rights of use for radio spectrum to third parties following a simple procedure and subject to the conditions attached to such rights and to competition rules, under the supervision of the national regulatory authorities responsible."

${ }^{46}$ ECC (2011a) Report on the description of practices relative to trading of spectrum rights of use. Available at: https://www.ecodocdb.dk/download/0e2afea8-17cc/ECCREP169.PDF (accessed: 22.04.2020)

47 Decision No 243/2012/EU of the European Parliament and of the Council of 14 March 2012 establishing a multiannual radio spectrum policy programme, OJ L 81 of 21 March 2012.

48 Decision (EU) 2017/899 of the European Parliament and of the Council of 17 May 2017 on the use of the $470-790 \mathrm{MHz}$ frequency band in the Union, OJ L 138 of 25 May 2017. 
bands as well. National provisions must be brought in line with Article 51 of the EU-ECC by 21 December $2020 .^{49}$

\subsubsection{Distinction between trading and leasing}

The notions of trading and leasing are not defined in the European legislation. Nevertheless, a number of observations can be formulated.

Trading of rights of use involves the transfer of spectrum usage rights and accompanying obligations - from one right holder to another party. In this case, that other party is granted a license by the competent authority to use spectrum following a commercial transaction with an existing license holder involving the transfer of the license rights and obligations. ${ }^{50}$ Trading can involve a partial or full transfer of the right holder's radio spectrum usage rights. In case of a full transfer, the accompanying obligations will be fully transferred to the recipient as well. In case of a partial transfer, both the original right holder as the recipient can be bound to the same obligations in the exercise of their respective rights. When rights are traded, their transfer is considered definitive and they do not revert back to the original right holder. ${ }^{51}$

Leasing, in turn, requires a contract allowing one party to exploit the rights of use of a right holder for a certain - usually limited - period of time. However, the original rightsholder maintains its license - and all rights and obligations that go with it. In such case, the right holder can exercise certain control over the party to which usage rights are leased. The leaseholder, however, does not in any way receive a license in its own right. When the lease expires, all rights revert back to the original right holder.

\subsection{National legal frameworks for spectrum sharing}

How did the EU Member States transpose the aforementioned provisions of European law regarding trading of spectrum usage rights? In this article we will only refer to some examples.

${ }^{49}$ Article 124 of Directive (EU) 2018/1972 of the European Parliament and of the Council of 11 December 2018 establishing the European Electronic Communications Code, OJ L 321 of 17 December 2018.

${ }^{50}$ ECC (2011aReport on the description of practices relative to trading of spectrum rights of use. https://www.ecodocdb.dk/download/0e2afea8-17cc/ECCREP169.PDF. (accessed:22.04.2020).

51 Ofcom (2011) Simplifying Spectrum Trading Spectrum leasing and other market enhancements. Available at: https://www.ofcom.org.uk/_data/assets/pdf_file/0030/62778/ statement-spectrum-leasing.pdf. (accessed: 22.04. 2020) 
In France, Article L42-3 of the Post and Electronic Communications Code $^{52}$ determines that the French Government can decide upon the frequencies in which licenses can be transferred. All intended transfers must be notified to Arcep, which will make those notifications public. When a frequency has been individually assigned or is used for the exercise of public services, the transfer is subject to prior approval by Arcep. Article R20-44-9-1 of the Code confirms that licensed frequency can be transferred entirely or partially. Article R20-44-9-2 reiterates the principle that individually assigned frequencies can only be transferred upon prior approval by Arcep. Other transfer intentions are only notified to the authority, which can oppose them. Article R20-44-9-3 provides that a request to Arcep must be filed jointly by the original right holder and the recipient. In the case of leasing, the notification must also include elements to guarantee the continuity of the public service missions for which the license to use frequencies is used, and details on how both parties aim to meet the obligations arising from the commitments resulting from their license.

Article R20-44-9-4 provides that a transfer involves the transfer of all rights and obligations relating to the usage right to the recipient. Both the original right holder and the recipient pay the fees for the rights they respectively hold at the end of the transfer. Some of the rights, however, must be divided proportionately. Article R20-44-9-5 provides that Arcep may only oppose a transfer if the general rules for obtaining a license are not met, if the rules for the transfer are not complied with, if there is a danger to effective competition on the market, if there is a non-compliance with the conditions set, or if a sanctions procedure has opened against one of the parties. Article R20-44-9-6 provides that Arcep may impose conditions to ensure compliance with earlier stipulated license conditions. Such conditions may relate to the use of the frequencies or frequency bands involved, or to the distribution of commitments made, if any, in the context of the license procedure. Article R20-44-9-7 adds that Arcep has six weeks to make its decision on the transfer. If the transfer is agreed upon, the original license must be revoked, and a new license must be issued to the recipient of the transfer.

Article R20-44-9-8 concerns leasing. Here, Arcep has three months to make its decision. Article R20-44-9-9 allows this period to be extended if there are reasons for a more thorough examination.

Article R20-44-9-10 provides that any transfer, together with Arcep's decision, must be made public. The National Frequency Agency will up-

${ }^{52}$ Code des postes et des communications électroniques. Available at : https://www. legifrance.gouv.fr. (accessed: 22.04.2020) 
date the frequency plan. Article R20-44-9-11 allows that the recipient requests to obtain the rights in absence of a response by Arcep. Article R2044-9-12 defines what information must be included in the public register of licenses.

In Germany, Article 55(8) of the German Telecommunications Act provides that a transfer of usage rights must be notified to the Bundesnetzagentur by submitting in writing a request thereto. The frequencies may continue to be used until a decision is taken. If all requirements for the use of radio spectrum are met, if there are no competition issues, and if there are no interference risks, the transfer should be approved. Article 62 of the same act provides that the Bundesnetzagentur can assign additional frequencies allowing trading. ${ }^{53}$

In the UK, Section 30 of the 2006 Wireless Telegraphy Act regulates spectrum trading. ${ }^{54}$ It provides that Ofcom may authorize transfers of spectrum licenses. Transfers under bands identified in the RSPP should be authorized. Both the original rightsholder and the recipient are to some extent bound to compliance with the terms of the license and the transfer. Partial transfers can be allowed, be it that regulations may restrict certain factors and that also here authorization by Ofcom is required. Upon transfer, the original license is surrendered and a new one is issued to the recipient. Ofcom may impose conditions on the transfer and may determine the procedure for the transfer. Time-limited transfers are also possible. Leasing is only possible if the license explicitly permits so, but where permitted does not require prior authorization by Ofcom.

The Wireless Telegraphy (Mobile Spectrum Trading) Regulations $2011^{55}$ provide that complete transfers are allowed when the rights and obligations of the original rightsholder become the exclusive rights and obligations of the recipient, or when the transferred rights and obligations become rights and obligations of the recipient while continuing, concurrently, to be rights and obligations of the original right holder. Partial transfers are also possible in those cases, if the transfer relates to part of the frequency range, part of the geographical scope of the license, or both.

${ }^{53}$ Telekommunikationsgesetz vom 22. Juni 2004 (BGBl. I S. 1190), das zuletzt durch Artikel 10 Absatz 12 des Gesetzes vom 30. Oktober 2017 (BGBl. I S. 3618) geändert worden ist (TKG).

${ }_{54}$ Wireless Telegraphy Act 2006, amended by the Electronic Communications and Wireless Telegraphy Regulations 2011. Available at: http://www.legislation.gov.uk/ukpga/2006/36/contents (accessed: 22.04.2020)

${ }_{55}$ Available at: http://www.legislation.gov.uk/uksi/2011/1507/made (accessed: 22.04.2020) 
Transfers are not allowed when not all parties consent thereto, when there are still fees to Ofcom outstanding, when the license has been revoked, when a license revocation request has been filed, or when Ofcom does not consent to the transfer.

Procedurally, the notification to Ofcom must identify both parties to the transfer, the license number, whether it is a full or partial transfer, the transfer agreement, and all other necessary information regarding the transfer or rights and obligations. Ofcom will publish that it has been notified and decide on the matter. Ofcom can authorize the transfer or give additional directions. Those directions can make the transfer conditional subject to compliance with certain requirements. Ofcom will take into account whether the rights and obligations of the license are met by the original right holder, whether the recipient can meet those obligations, whether competition will be distorted, or whether there are matters of national security or international arrangements at stake. Following its authorization, Ofcom will issue a new license to the recipient and revoke the original license. The decision will be made public.

An overview of license trades can be found in Ofcom's Spectrum Information Portal. ${ }^{56}$

In the Russian Federation, since the overall legal nature of the radio spectrum is not fully clear in the codified Russian laws (e.g. Civil Code of the Russian Federation), the possibility of "leasing" spectrum does not exist. The permission for the use of frequencies always indicates the entity (or person) responsible for using the allocated frequency band. In case of any troubles/violations, the regulatory body will communicate with this entity only. The participation of any third party is not considered. As already mentioned, the purpose of using certain frequencies should be indicated in the application. If a commercial organization intends to use frequencies for commercial purposes, then transferring permission to another person for non-commercial (research) use is impossible. However, if a frequency sharing scheme is already being introduced, when submitting an application, the applicant agrees in advance with the possibility of using the same frequencies by third parties in agreement with them. This began to happen often by agreement between mobile operators in different regions of Russia, in which one of them has a spectrum deficit. However, the purpose of using the spectrum must remain the same.

${ }^{56}$ Available at: https://www.ofcom.org.uk/spectrum/information/spectrum-information-system-sis/spectrum-information-portal (accessed: 22.04.2020) 


\section{Conclusion}

In our study, it was found that all EU Member States offer the possibility to obtain a license for the use of radio spectrum for research, testing, and experimental purposes. However, as this is not an EU-harmonized matter, the procedures, requirements, and costs for obtaining such license vary significantly. Also, the duration of these licenses varies greatly, going from just a few weeks in some Member States to several years - including potential renewals - in others, with the average being up to one year. Also, there is no procedure to obtain a license for cross-border testing and experimental purposes. As a result, when a test or experiment would span several Member States, licenses would have to be obtained in each of those states. However, given the lack of coordination in this matter, there is also no guarantee that licenses in the same frequency bands can be obtained in such cross-border settings.

With regard to the primary frequency market, the main finding is therefore that it is principally possible to obtain licenses for research, testing, and experimental purposes in all EU Member States, including in the current $3 \mathrm{G}$ and $4 \mathrm{G}$ bands. However, given that such licenses are generally awarded for a fairly short duration only, and given the lack of coordination in terms of available bands for these purposes at the EU level, the general conclusion is that this method does not allow for the creation of a persistent and pan-European network of wireless capacity for research, testing, and experimental purposes. While most EU Member States do already have tests in $5 \mathrm{G}$ bands ongoing, there are no clear indications that this would directly result in the creation of a more permanent research infrastructure within the $5 \mathrm{G}$ spectrum.

The question is then whether there are possibilities on the secondary market, i.e. by obtaining radio spectrum from a licensed operator either through transfer of license rights and obligations or by renting or leasing part of that operator's spectrum. Here, it is clear that the European legislator has taken the necessary steps to make this possible by requiring Member States to implement procedures for license transfers and leases, within a number of frequency bands defined in the RSPP. In this field, there is therefore at least a certain baseline of harmonization, although the precise procedures can still vary between Member States. Overall, it was found that Member States require prior notification of the intended transfer or lease to the competent authority. This authority will generally do a number of checks, mainly to verify that licensing requirements are complied with and that the transfer or lease does not disturb competition on the market. 
If everything is found correct, the authority will authorize the transfer or lease. Only in one Member State it was found that the competent authority must only be notified but does not have to give prior authorization. Overall, the procedures for this were found to be fairly similar across the board.

Can transfers or leases then provide a solution to the spectrum needs of the research community? Leases offer the benefit that they are easier to obtain in the sense that the license rights and obligations principally remain with the original right holder. The recipient will only receive the right to use part of the right holder's spectrum, under the conditions set by the lease. This allows, for instance, for agreements to be made on the placing of base stations. While leases are considered as being of limited duration, there do not seem to be explicit maximum durations, be it that the lease can of course not outlast the license itself. It can therefore provide a more durable solution than the short-term licenses for research, tests, or experiments found on the primary market. Transfers would of course make for an even more persistent solution, as here all rights and obligations are transferred for the complete duration of the license. However, such transfer also implies that the recipient of the transfer must comply with all license requirements, which in some Member States requires the presence of a legal person registered as an operator.

Briefly summarizing, the necessary European level regulation exists that would allow for example LSA type of flexible spectrum management to be applied between researchers and commercial mobile network operators (MNOs). In addition, standardised technical specifications exist in 3GPP for implementing the LSA in the way that they have been specified by the regulatory authorities. The remaining obstacle is the weak position of researchers and research institutions to enter into the negotiation and conclusion of agreements with MNO's. One of the possible remedies is to assign this task to a specialised entity, preferably at the EU level. A study investigating the feasibility to establish such kind of entity is the objective of the Eu Wireless action, funded by the European Commission under the Horizon 2020 programme. In addition, political support, for example in the form of an EU Recommendation, to overcome the reluctance of MNOs to share their spectrum usage rights with the research community would be most welcome.

\section{相 References}

1. AnkerP. (2017) From spectrum management to spectrum governance. Telecommunications Policy, vol. 41, pp. 486-497. 
2. Beltrán F. (2016) A Review of the Evolution of Auctions As a Method for Radio Spectrum Assignment. Available at: http://dx.doi.org/10.2139/ ssrn.2828543. (accessed: 22.04 2020)

3. Beltran G. (2017) Accelerating the introduction of spectrum sharing using market-based mechanisms. IEEE Communications Standards Magazine, no. 1, pp. 66-72.

4. Berge E., Kranakis E. (2011) Technology-dependent commons: the radio spectrum. International Journal of the Commons, pp. 86-91.

5. Brito J. (2006) The Spectrum Commons in Theory and Practice. Stanford Technology Law Review.

6. Cave M., Nichols R. (2017) The use of spectrum auctions to attain multiple objectives: Policy implications. Telecommunications Policy, no. 5-6, pp. 367-378.

7. Coase R.H. (1959) The Federal Communications Commission. The Journal of Law and Economics, pp. 1-40.

8. Cramton P. (2013) Spectrum auction design. Review of Industrial Organization, vol. 42, pp. 161-190.

9. Dahlberg C. et al. (2013) A techno-economic framework of spectrum combining for indoor capacity provisioning. In: Proc. IEEE24th Int. Symp. Pers. Indoor Mobile Radio Commun. London: IEEE, pp. 2759-2763.

10. Donovan J. (2019) How Do Wireless Networks Transmit Data. Available at: https://blog.commscopetraining.com/how-do-wireless-networks-transmit-data. (accessed: 22.04. 2020)

11. Ellingson S.W. (2016) Radio Systems Engineering. Cambridge: Cambridge University Press.

12. Feasey R. (2015) Confusion, denial and danger: The response of the telecommunications industry to the challenge of the Internet. Telecommunications Policy, vol. 39, pp. 444-449.

13. Hardin G. (1968) The Tragedy of the Commons. Science, vol. 162, No. 3859, pp. 1243-1248.

14. Herter C.A. (1985) The Electromagnetic Spectrum: A Critical Natural Resource. National Resources Journal, vol. 25, issue 3. pp. 651-663.

15. Hook S.A. (1993) Allocation of the Radio Spectrum: Is the Sky the Limit? Indiana International \& Comparative Law Review, vol. 3, pp. 319360.

16. Martin O. (2012) The "Hidden" Prehistory of European Research Networking. Bloomington: Trafford Publishing. 126 p.

17. Matinmikko-Blue M. (2018) Stakeholder analysis for the development of sharing-based spectrum governance models for mobile communications. PhD dissertation. University of Oulu. 
18. Olla P., Patel N. (2002) A value chain model for mobile data service providers. Telecommunications Policy, no. 26, pp. 551-571.

19. Ostrom E. (1990) Governing the commons: the evolution of institutions for collective action. Cambridge: Cambridge University Press.

20. Rishabh D. (2016) Governing Spectrum Commons. TPRC 44: The 44th Research Conference on Communication, Information and Internet Policy.

21. Samuelson P. (1954) The pure theory of public expenditure. The Review of Economics and Statistics, no. 4, pp. 387-389.

22. Shokhin V.D. (2010) Nature and Assignment of the Permission System. Herald of Moscow State University. Law, no. 6, pp. 63-64. (In Russ.).

23. Stahov A.I. (2009) Public Administrative Measures for Providing Security. Zakony Rossii: opyt, analiz, praktika = Russian Laws: Experience, Analysis, Practice, no. 9, pp. 25-29. (In Russ.).

24. Subanova N.V. (2012) Permissive Powers of Executive Bodies in Russian Federation. Moscow: Jurisprudencia, 288 p. (In Russ.).

\section{Information about the authors:}

J. Dumortier - Partner, Lawyer.

I.Yu. Bogdanovskaya - Doctor of Sciences (Law), Professor.

N. Vandezande - Legal Consulter.

M.V. Yakushev - Senior Lecturer.

The article was submitted 12.10.2020; approved after reviewing 11.10.2021; accepted for publication 01.11.2021. 